\title{
LA MÚSICA MILITAR EN TIEMPOS DEL GENERAL SAN MARTÍN
}

\author{
Amalia Roales-Nieto y Azañón \\ Universidad Complutense de Madrid. España.
}

La música militar como arte debe combinar el sonido y el ritmo para comunicar al guerrero un espíritu patriótico y un sentido moral del valor y la disciplina.

\section{ANTECEDENTES HISTÓRICOS:}

En la belleza de los sonidos existe una potencia misteriosa que incide en el alma de los pueblos y domina con pasión el genio de los grandes artistas pero rehusa descubrir este misterio a la curiosidad investigadora del hombre.

Las primitivas civilizaciones envolvían estos misterios con los mitos sagrados unidos a las teogonías, ocultaban con ello la ignorancia del ser humano ante los fenómenos que sobrepasan su entendimiento más o menos filosófico. De siglo en siglo y desde los más remotos tiempos ha crecido la magnificencia del lenguaje musical y la diversidad de su poder expresivo.

En el desarrollo milenario de nuestra historia el ritmo de la danza y la música guerrera son inseparables; el hombre utiliza su propio cuerpo como medio rítmico visible de expresión personal, utilizando el sonido ritmado para su comunicación auditiva con los otros seres humanos. Antes que los trazos de las siluetas de toros o caballos, el hombre prehistórico conoció la alegría del ritmo, la excitación personal con el grito modulado al estilo de los animales salvajes a los que disputaba sus presas y su hábitat. El hombre com- 
batía profiriendo clamores de amenaza y entre los útiles de su primitivo menaje se han encontrado piedras que entrechocaba para acompasar sus cantos o sus pasos. La música aparecerá siempre unida a las manifestaciones elementales de la sociedad como la expresión natural de los sentimientos anímicos.

Los hombres antiguos de Egipto, Sumeria, Babilonia, Persia, Grecia o Roma utilizaban instrumentos con la doble finalidad que mencionamos: guerrera/pastoril, guerrera/procesional etc. utilizando cuernos, colmillos de elefante, trompetas, tambor con o sin percutores, crótalos, crúsmata (primitiva castañuela) etc. Las caracolas marinas que la Mitología coloca entre las manos de los Tritones, fueron, quizá, los primeros instrumentos de viento cuyos roncos sonidos emitidos con el soplo humano, vinieron en ayuda de la voz para propagar a distancia el sonido de las señales acústicas. Cuando el hombre supo fundir los metales se explotaron en este mismo sentido sus propiedades sonoras consiguiendo aumentar la potencia, la reverberación y la escucha a mayor distancia.

La Biblia hace de Turbacain, hijo de Lamec, el primer herrero y de su hermano Jubal el primer constructor de instrumentos metálicos. Moisés, al mandato divino, según narra el libro "Números" (vers. 10, 1-10) hizo forjar trompetas de plata batida reservadas después como objetos sagrados bajo custodia de los sacerdotes, pero que debían sonar de diferente forma para la salida y marcha de los hebreos. Estas trompetas resonarían como "clamor" en los combates. Su doble finalidad religiosa y militar, en este caso, bélica, se describe en el asedio de la ciudad de Jericó: "durante seis días los soldados de Josué recorrían procesionalmente, en silencio, el contorno amurallado de la ciudad que derribaron el día séptimo con el sonido de las siete trompetas y de los gritos proferidos al unísono por el pueblo que seguía el Arca de la Alianza"; símbolo perfecto de estrategia sonora y de terror que una concepción de la música guerrera adecuaba al uso del momento.

Es el mismo principio que utilizó Gedeón en el ataque nocturno del campo de las Madianitas, añadió al sonido de las trompetas el estruendo imprevisto de cacharros de terracota que se rompían a un mismo tiempo. Vemos con ello que uno de los fines de la música guerrera responde al criterio de querer amedrentar al adversario con gritos amenazantes y sonidos estruendosos. Se comprueba que el efecto de estos sonidos no es percibido exclusivamente por el enemigo; en los ritmos, fórmulas que se hacen familiares poco a poco, en los textos de los himnos que hay que recordar y a los que el canto comunica una potencia irresistible, el combatiente experimenta más valor, más decisión, y un sentimiento reconfortante ante la unanimidad del esfuerzo y la percepción de la muerte. Al mismo tiempo percibe la coor- 
dinación rítmica de las señales sonoras que regulan el movimiento de las tropas, propagando en la distancia las ordenes convertidas en signos sonoros comprensibles. Estos toques de órdenes realzan el honor de los triunfos o la tristeza de la derrota. Los hombres antiguos no ignoraban estos principios y supieron adaptarlos a las necesidades del momento y de los toques que utilizaban.

Saltando siglos en la Historia citaremos como precedente de nuestro estudio, el siglo XVI hasta llegar a la época vivencial del General José de San Martín.

En el siglo de los Médicis, algunos escritores comienzan a sentir la importancia de la música militar y el juego que producen ciertos instrumentos musicales en las constantes batallas. Maquiavelo hablaba del tamboril de las tropas italianas que sabían conseguir diversas señales diferentes de toque $y$ nos afirma que los "condottieri" fueron los primeros en utilizar el tamboril acompañado del caramillo y del "arigot" (especie de flauta de origen provenzal).

El siglo XVI en España fue el de las heroicas aventuras, el de la conquista y fundación en Hispano-América; el siglo XVII fue el de la paz hispánica en el Nuevo Mundo mientras que el siglo XVIII tuvo una importancia capital en la formación del espíritu americano, distinto al de la Metropoli, presintiéndose en él los anhelos de la emancipación y la libertad.

En el siglo XIX, el académico y compositor Francisco Asenjo Barbieri estudió la música militar siendo comisionado por la Reina María Cristina para estudiar en Europa cómo se regulaba la música militar en los distintos regimientos de Alemania o de Francia. Nos aporta Barbieri noticias sobre la música militar y dice 2. "En el siglo XVI los ejércitos españoles contaban con un instrumento músico-militar, nuevo, no de origen musulmán como el tambor o los timbales, sino de los soldados suizos que habían servido en la Guerra de Granada y a la sazón servían en Italia a las órdenes del Gran Capitán. Dicho instrumento se llamaba Schweizerpfeife o Feldfeife, es decir, pito de Suiza que pasó a nuestra lengua con los nombres de "pífaro" o "pífano", o simplemente pito, sirviendo desde entonces a nuestras tropas de infantería, hasta que desaparecíb modernamente, usándose hoy tan sólo en el Real Cuerpo de Alabarderos. De lo dicho resulta que en el siglo XVI los instrumentos de música que podremos llamar de ordenanza en los ejércitos de España eran las trompetas y timbales para la Caballería y los tambores y pífanos para la Infantería (...). Al venir a España Carlos de Gante vino detrás de él una multitud de flamencos y alemanes, entre ellos muchos artistas de talento que contribuyeron a los adelantos del arte músico en España (...). En su propio palacio se formaron dos grupos de artistas músicos para el servicio 
religioso, divididos por nacionalidades, con los nombres de Capilla Española y Capilla Flamenca; en lo militar se formó igualmente la Guarda Alemana y La Guarda Española y si a esto se agrega que Carlos $V$ era, no sólo un gran capitán, sino un buen músico... habrá que conceder que en su tiempo se engrandecería mucho la música militar. (...) Sin embargo, hay un dato contrario a esta idea: En las Ordenanzas de 1525 se mandó suprimir los atabales, dejando sólo dos trompetas en cada capitanía... hecho razonado en aquellos tiempos de tantas batallas dado el gran volumen de los timbales... A cambio de esto hallamos por todas partes noticias del gran aparato musi$\mathrm{cal}$ con que se celebraban las fiestas y triunfos de entonces conservando los timbales en las ciudades $y$ aun las tropas en tiempos de paz. El mismo Felipe II, tan respetuoso para con su padre tenía 10 trompetas y seis timbaleros adjuntos a su Real Caballeriza".

Y continúa Barbieri diciéndonos: "A mediados del siglo XVII cada tercio español se componía de tres mil hombres, repartidos en doce compañías con dos atambores y un pífano cada una, lo cual daba un total de venticuatro atambores y doce pífanos. El jefe inmediato de esta banda de músicos se llamaba "Tambor Mayor". A este Tambor Mayor se le exigían una serie de cualidades además de ser músico, tenía que sufrir esámenes para conseguir su plaza, conocer idiomas y poseer una serie de conocimientos que lo convertían casi en un diplomático o enlace entre ejércitos contrarios." ${ }^{3}$

Respecto a las tropas de Caballería, utilizaban una trompeta en los Toques de Guerra conocida como "trompeta italiana" mientras que para otros usos bélicos se utilizaba la "trompeta española" y la "trompeta bastarda". También sabemos que el "Trompeta Mayor" de Caballería hacía los mismos oficios que el Tambor Mayor de Infantería, sirviendo como parlamentario en las contiendas y gozando de los mismos privilegios e inmunidades."

Durante la Guerra de España contra Portugal, aliada de Inglaterra, Don Pedro de Ceballos salió de Buenos Aires con un ejército de dos mil hombres, atacó la Colonia y la rindió por capitulación el 2 de noviembre de 1762. En un documento de la época se describe su entrada en la plaza fuerte $\mathrm{t}^{4}$ "A la una del día se tocó en el campamento la "Asamblea", a las dos "La Marcha" y se puso la tropa en movimiento en el siguiente orden: los lacayos de S.E. con caballo cubierto; cuatro Dragones sable en mano, dos Capitanes, el Capellán Mayor y el Auditor de Guerra, todos a caballo. Le seguía el Mayor General con 12 Dragones a pie y alternaban con "las caxas y pifanos" o que batían ya la Marcha Dragona y ya la de Infantería..."

Otro testimonio se nos ofrece en las ceremonias realizadas en Buenos Aires, en julio y agosto de 1789 , a la muerte del Rey Carlos III y la corona- 
ción de Carlos IV, rindió honores una Compañía de Granaderos Reales, con toda su oficialidad, clases, tambores y pífanos...

Con esto quiero decir que en el siglo XVIII, se cambiaron los reglamentos, los uniformes, las armas y hasta las Ordenanzas. Fue el Rey Carlos III quien ordenó recopilar y concertar la famosa colección de "Toques de Guerra", fueron recopilados por Manuel de Espinosa, músico de la Capilla Real y publicados en Madrid por Juan Moreno Tejada en 1769. Contiene esta colección los "Toques reglamentarios de la Infantería Española" y los "Toques de Trompetas de la Caballería". El compositor Don Nemesio Otaño, S.I. los dio a conocer en un memorable concierto realizado en Valladolid (1940), además de haber armonizado cada uno de ellos. ${ }^{5}$

En el estudio que realizó dice lo siguiente: "No sé precisar su origen; pero sin fundamento puedo suponer que varios - los principales - datan de anteriores épocas no sólo en razón de intrínseca y formal contextura, más también porque se encuentran reflejados en esa literatura musical guerrera, ya desde el siglo XVI, y sobre todo en el XVIII (...) Se puede deducir y asegurar que estos toques, coleccionados en 1769 son en su mayoría de época anterior, posiblemente de los tiempos imperiales. En el siglo XVII, quizá, por exigencias instrumentales al pasar de las severas y categóricas trompetas del $\mathrm{XVI}$ a los instrumentos de vientos, más flexibles, tipo chirimía u óboe, sufrieron ligeras modificaciones de contorno y floreo que les da un aire estilístico de época. Probable es que los toques se hibiesen formado en ese siglo y alguno, tal vez, en pleno siglo XVIII. Sin embargo cuando se estudia nuestra literatura militar, sobre todo, en las Ordenanzas, se encuentra una rigurosa exigencia reglamentaria, por la que queda asegurada la conservación neta de los Toques tradicionales usados por la tropa española (...) ahora bien, si se considera cuán grande es en el Ejército el respeto a la tradición esta insistente vigilancia de las Ordenanzas por la pura conservación de los Toques de mando y la escrupulosidad con que se enseñan y se exigen aun en los menores detalles rítmicos, tiene una fuerza de convicción irresistible. ${ }^{6}$

En este álbum de "Toques de Guerra" hay los siguientes títulos:

Generala, Asamblea, Bandera o Tropa, Marcha de fusileros, Marcha de granaderos, Alto, Retreta, Bando, Lamada, Misa, Oración, (tambor sólo) Orden, (tambor sólo) Fagina, Diana (tambor sólo) Ataque, siguiendo la tradición de 1769.

El Apéndice incluye Toques de trompeta: A degüello, La llamada, y la Oración o Diana, Además incluye los "Puntos de Guerra" que deberá observar la Caballería: La Batalla o Botasilla, Asamblea, A caballo, y La Marcha. 
Y así, casi sin darnos cuenta hemos llegado al tiempo vital del General don José de San Martín y Matorras (Yapeyú, Argentina 25-2-1778; Boulogne-sur-Mer, 17-8-1850)..

Dice San Martín de sí mismo: Yo serví en el Ejército Español, en la Península, desde la edad de 13 a 34 años hasta el grado de teniente coronel de Caballería" ?

Es indudable que el general San Martín llevó a Chile, Perú y Argentina el espíritu militar espanol, asimilado, practicado y enriquecido con valores personales propios conseguidos a lo largo de sus 22 años de servicio en el Ejército Español. Este espíritu es el que inculcó a sus tropas empleando las mismas Ordenanzas Militares de su época que eran las decididas por Carlos III y publicadas en $1769^{\circ}$. Pienso que también adoptó las Ordenanzas sobre Toques Militares que ya he expuesto anteriormente al crear el Primer Escuadrón de Caballería del Ejército de los Andes. Apenas rastreamos entre la multitud de estudios realizados sobre esta noble figura del general San Martín, un gusto para la música propiamente dicho, tampoco sus tiempos de guerra y campañas militares le dejarfan tiempo para ello, aunque sabemos que tocaba la guitarra no lo he podido probar documentalmente. Si sabemos que en el programa de estudios militares la Música estaba incluida entre otras materias como la Geografía, Latín, Francés, o Matemáticas. Aquí tendríamos el primer indicio de su base musical; el segundo nos lo da su permanencia de 22 años en el Ejército. Los regimientos de Murcia, Voluntarios de Campo Mayor, Caballería de Borbón, Dragones de Sagunto, etc. en los que la disciplina militar se llevaba con toda rectitud y apego a la tradición castrense. Ya en América convertido en educador de tropas -fundó el Primer Escuadrón de Granaderos a caballo y organizó una Academia de Instrucción práctica que dirigia personalmente. Exigía disciplina y orden, amor a la libertad, valor y dedicación plena a todos sus soldados- también aplicó las Ordenanzas musicales o "Toques militares" porque leemos lo siguiente:

..."Así en vísperas de la segunda invasión inglesa, el 15 de enero de 1807 en ocasión de realizarse la revista general de tropas en el campo de Barracas (...) se puntualiza que las bandas militares rompieron "la Generala", es decir, iniciaron con sus sones la parada militar ${ }^{9}$...

En los distintos partes de guerra, también se mencionan los instrumentos musicales capturados y los requerimientos de San Martín pidiendo material musical para sus ejércitos. El historiador José María PAZ nos relata en sus "Memorias" que en el otoño de 1814 siendo San Martín Comandante en Jefe del Ejército del Norte, la banda militar, siguiendo una costumbre tocaba la "Retreta" en la puerta de la casa del general. ${ }^{10}$ 
"Dos meses después de haber proclamado San Martín la Independencia del Perú, el 28 de julio de 1821, tiene lugar la capitulación de las tropas españolas existentes en las fortalezas del Callao (...) El artículo primero de dicha capitulación es un homenaje a los héroes españoles que resistieron bravamente. Dice así:

"La guarnición de la plaza del Callao, saldrá por la puerta principal, con rodos los honores de la guerra, dos cañones de batalla, bandera desplegada y tambor batiente" "...

¿Qué otra cosa ordena don José de San Martín aparte de tratar caballerosamente a los vencidos, sino recuperar el rango que tenía el Tambor Mayor en cualquier circunstancia bélica?. Si utiliza el "tambor batiente" con un toque que debe ser misterioso y expectante un toque de respeto ¿no utilizaría también las trompetas a caballo y los pífanos con la Infantería?

En el primer bando dirigido a los argentinos restauradores de la libertad en Chile, dice:

"No venis a hacer conquistas sino a liberar a los pueblos... el que robase o tomase por valor de dos reales para arriba, sería pasado por las armas, previo consejo de guerra verbal sobre el tambor ${ }^{n}$... ${ }^{12}$

De nuevo aparece el Tambor para ser testimonio de un posible ajusticiamiento, de una muerte merecida en Consejo de Guerra, con el Tambor mayor como protagonista de una historia triste...

El último testimonio que voy a citar es el relativo al Himno Nacional del Perú, publicado junto a otros himnos en Argentina. Nos demuestra este documento que existió en el Perú en 1821, tiempo del General San Martín, una banda de música militar y que este himno se escribió cuando él pudo escucharlo y quizá, cantarlo. El texto, muy patriótico y exultante es el primero que menciona al General San Martín y sus hechos gloriosos. Su pone además la transición entre los cantos hispánicos y los surgidos de la emancipación.

Con los testimonios aportados hemos visto cómo el general San Martín continuó con la tradición hispana de la música militar, la admitió e implantó como necesaria. Así mismo aceptó los instrumentos de viento y de percusión propios para Toques militares, en tiempos de guerra y en tiempos de paz. Ellos serían los testigos de sus hechos gloriosos, de sus momentos de abatimiento, del majestuoso paso de los Andes y de los honores victoriosos que tributa la ciudad.

Con la paz y la libertad, con la independencia y la emancipación se crearon nuevas músicas marciales, nuevos himnos, canciones patrióticas o canciones políticas que utilizará el pueblo a favor de sus benefactores o en 
contra de sus tiranos, serán las nuevas armas en boca de las gentes, que indefensas, utilizan un lenguaje expresivo que también se comunica se comunica en la distancia. Cito un ejemplo de canción surgida en España a raíz de la invasión napoleónica:

"A las armas corred, patriotas,
a lidiar, a morir o vencer,
guerra eterna al infame tirano,
odio eterno al impío francés".

O esta otra con una ironía no carente de gracia:

"Con las bombas que tira

el Mariscal Soult, se hacen las gaditanas

mantillas de tul."

El abanico de temas marciales es tan amplio que ya no tiene cabida en este pequeño trabajo. En Europa, última permanencia del general San Martín, los himnos patrióticos de HAENDEL "God save the King", "La Marseillaise" de Rouget de Lisle o el "Deutschlandlied" de HAYDN no son sino una prueba más de los sentimientos nacionalistas de su momento histórico.

En la época en que los países hispano americanos formaban parte de España, es lógico aceptar que las marchas militares fueran las del Ejército español, deducción ratificada por las referencias contenidas en los documentos del pasado, de incuestionable veracidad y valor comprobable. Que los "Toques de Guerra" cuya recopilación ordenara Carlos III en su momento, datan como mínimo de los siglos XVI y XVII. Que con el transcurso del tiempo han sufrido ligeras variantes debido a las nuevas técnicas y nueva aportación instrumental o, quizá, al influjo de otras milicias extranjeras.

De entre todas las composiciones conservadas tradicionalmente cito: "La Marcha de Fusileros" y "La Marcha de Granaderos".

La "Marcha de Fusileros" se usaba en desfiles y paradas, siendo considerada hasta el momento presente la marcha especial para la Infantería. La otra marcha usada por los ejércitos españoles tanto en la Península como en Ultramar, es "La Granadera". Marcha que por Real decreto (3-9-1770) fue declarada "Marcha de Honor". Desde entonces se interpreta en España como marcha para rendir honores al santísimo Sacramento y a las personas de la realeza. Después se ha considerado esta marcha "Himno Nacional" hasta 1931. En 1937 por Decreto de la Jefatura del Estado, ratificado por otro de la Presidencia del Gobierno del 17 de julio de 1942, se declara que esta Marcha Granadera sea el Himno Nacional de España que "será ejecutado en los actos oficiales, tributándole la solemnidad, acatamiento y respeto que el 
culto a la Patria requiere" ${ }^{13}$. En Argentina y otros países de América se han renovado estas composiciones y se interpretan de vez en cuando en ocasiones muy especiales como homenaje a los Patricios de la Patria -1968 y 1969-. También se cita en las Actas Capitulares, utilizadas documentalmente por Bartolomé MITRE en su obra "Historia de Belgrano y de la Independencia Argentina"; BB, Aires, 1887, tomo I de la cuarta edición, pág. 192. nos testimonia el empleo de un toque llamado Ataque. A degüello o calacuerda.

A la muerte del general San Martín en 1850 la música militar comienza una decadencia. Las guerras van apaciguándose poco a poco y las bandas militares ocuparán un puesto de lujo o superfluo, en toda la sociedad europea. Se escuchará su música pacíficamente, en los jardines al aire libre, en las plazas, en los desfiles de tropa o en cualquier homenaje patriótico.

A principios del siglo $\mathrm{XX}$, cada uno de los países independientes de Hispano América va modificando los Toques reglamentarios de sus ejércitos y fueron adquiriendo su propia personalidad individualizada, especialmente en la Argentina donde cada toque tenía plena identidad, cada uno de ellos anunciaba el desarrollo de una actividad diferente, una determinada especialidad: Infantería, Caballería, Artillería, Sanidad, etc. Los toques reglamentarios, existen siempre, son necesarios en todos los ejércitos, y responden a la tradición y actividad castrense, fuente que alimenta sin cesar el espíritu de cada soldado.

Termino esta síntesis histórico-militar aduciendo, una vez más, los pensamientos de mis primeras páginas: la música militar, religiosa o profana es todavía un misterio para el ser humano. Pese al progreso científico y la tecnología en el Arte de la Guerra, ahora se intenta suprimir la Música viva en casi todos los Ejércitos.

Afirmo que los Toques Militares y las Ordenanzas dictadas por el rey Carlos III se conservan todavía hoy en los Regimientos de Hispano América y debemos al general san Martín y a sus colegas e ilustres militares de estirpe hispánica el paso del Atlántico de esta música, desde la Metrópoli Real al Nuevo Continente Americano.

Ruego a Dios que todavía encontremos compositores e intérpretes para que esta noble tradición sonora con milenios de antigüedad no se extinga de nuestro mundo en el que actualmente imperan las grabaciones distorsionadas, deformadas, grabaciones frías, sin sentimientos, un mundo en que los ruidos son la antítesis de lo melódico y de lo marcial, así como de los sentimientos más profundos: el amor a la PAZ y a la PATRIA valores permanentes en el acervo de nuestros PAISES HERMANOS. 